\title{
Abortion, ectopic pregnancy and miscarriages in Sub Saharan Africa: Challenges of Rhesus isoimmunisation in Rhesus negative women
}

\author{
O. Erhabor ${ }^{1 *}$, Z. Isaac ${ }^{1}$, A. Yakubu ${ }^{2}$, T. C. Adias $^{3}$ \\ ${ }^{1}$ Department of Haematology and Transfusion Medicine, Faculty of Medical Laboratory Science Usmanu Danfodiyo University, \\ Sokoto, Nigeria \\ ${ }^{2}$ Department of Obstetrics and Gynaecology, Usmanu Danfodiyo University, Sokoto, Nigeria \\ ${ }^{3}$ College of Health Technology Bayelsa State, Nigeria \\ Email: $\stackrel{*}{n}$ osaro@yahoo.com
}

Received 19 September 2013; revised 15 October 2013; accepted 23 October 2013

Copyright (C) 2013 O. Erhabor et al. This is an open access article distributed under the Creative Commons Attribution License, which permits unrestricted use, distribution, and reproduction in any medium, provided the original work is properly cited.

\section{ABSTRACT}

The implementation of a program on routine antenatal anti-D prophylaxis (RAADP) in the developed world has led to a significant decline in the residual numbers of Rhesus negative women becoming sensitized. However, a significant number of Rhesus D negative women in SSA are not fortunate because of lack of access to prophylactic immunoglobulin $D$ and thus they continue to be affected. The management of Rhesus negative pregnancy in Sub-Saharan Africa is associated with several daunting challenges: absence of a policy on universal access to $\mathrm{Rh} D$ immunoglobulin, lack of fetomaternal testing facilities, unaffordability of prophylactic anti-D immunoglobulin, poor uptake of quality antenatal care, poor health infrastructure, sub optimal management of potentially sensitizing events during pregnancy, shortage of qualified medical personnel, poor data management, high incidence of illegal abortion and quackery. There is a need for the formulation of necessary guidelines on Rhesus immunoprophylaxis in SSA. Health authorities need to implement evidence-based policy on universal access to anti-D immunoglobulin. There is also the need to optimize the knowledge of obstetricians on anti-D prophylaxis, implementation of the readily available and affordable Kleihauer fetomaternal haemorrhage testing for all women who experience a potentially sensitizing event antenatally post 20 weeks gestation and postnatally. These factors can facilitate the effective management of $R h$ negative pregnancy in the region and reduce the risk of Rhesus $D$ immunization and Rhesus $D$ haemolytic disease of the foe-

"Corresponding author. tus and newborn.

Keywords: Abortion; Ectopic Pregnancy; Miscarriages; Sub Saharan Africa: Rhesus Isoimmunisation

\section{INTRODUCTION}

The term pregnancy refers to an ovum fertilized by spermatozoa implanting itself to the maternal uterus with subsequent development of an embryo and growth into a foetus over a mean period of 9 months. Implantation of the foetus in any site other than a normal uterus location is termed ectopic pregnancy and is abnormal. The period of development and growth within the maternal uterus is known as gestation and is estimated to last approximately for 40 weeks or 280 days from fertilization to parturition (labour). This is subject to variation and any duration between 38 and 42 weeks is considered normal. From the 6th week gestation, Rh D antigen is fully developed and entrance of foetal red cells into maternal circulation can potentially sensitize the mother to produce immune antibody-D. A pregnant woman can make Rhesus IgG blood group antibodies if her foetus has a blood group antigen that she lacks. This can happen if some of the foetus blood cells pass into the mother's blood circulation (fetomaternal haemorrhage) during pregnancy or at the time of childbirth or during obstetric intervention of pregnancy, such as external cephalic version (ECV), abdominal trauma, missed miscarriage, amniocentesis, cordocentesis, ruptured ectopic pregnancy, miscarriage, medical or therapeutic termination of pregnancy and illegal abortion. The mother can also potentially produce alloantibodies if there is feto-maternal haemorrhage from any of the above potentially sensitizing events [1]. This 
alloantibody can potentially destroy her future baby's red cells if the baby is positive and can cause severe Rhrelated haemolytic disease of the foetus and newborn (HDFN). One of the major advances of the twentieth century medicine is the prevention of HDFN by stopping the formation of Anti-D antibodies by D negative mothers with an injectable prophylactic medication called Rho (D) immune globulin [2]. Although the implementation of a program of routine antenatal anti-D prophylaxis (RAADP) has led to a significant decline in the numbers of women becoming sensitized in most developed countries, a significant number of women who are not fortunate enough to have access in SSA continue to be affected [3]. Transplacental or fetomaternal haemorrhage (FMH) may occur during pregnancy following a potentially sensitizing event such as abortion and miscarriage or at delivery and lead to immunization to the $\mathrm{D}$ antigen if the mother is Rh-negative and the baby is Rh-positive. This can result in haemolytic disease of the foetus and new-born (HDFN) in subsequent D-positive pregnancies. In most settings in SSA, no alloimmunization prevention follows potentially sensitizing events during pregnancy. During medical termination of pregnancy in Rh-negative women, there is no universal access to prophylactic immunoglobulin D among Rhesus negative pregnant women, and information about previous pregnancies and termination is often lacking in patients' medical notes due to poor data management. These issues have negative effects on the effective management of Rh-negative pregnancy. Red cell immunization during pregnancy remains a major challenge to obstetricians and transfusion practitioners in SSA. Although being absent in most settings in SSA, it is the best practice to screen all antenatal women for their ABO, Rhesus D blood group and for the presence of clinically significant alloantibodies in early pregnancy. This is to enable remedial action to be taken if the women are found to be $\mathrm{Rh} \mathrm{D}$ negative or positive for a clinically significant antibody that has the potential to cause HDFN. A foetal genotype test is carried out to determine if the developing foetus is carrying the antigen to which the maternal alloantibody is specific and lacking. An amniocentesis test is carried out on a mother who is positive for a clinically significant alloantibody with an increasing antibody titre to determine the potential risk to the developing foetus. In severe cases of HDFN, intrauterine transfusion may be indicated to manage the resulting anaemia in the developing foetus. All these evidenced-based best practices are not available in most settings in SSA and negatively impacts the immuno-haematological services and care offered to these pregnant women.

It is the best practice to carry out Feto Maternal Haemorrhage (FMH) testing on all Rh-negative women who undergo termination of pregnancy, miscarriage and those delivered of a Rh-Positive baby within 72 hours, to determine the volume of foetal red cells that may have entered the maternal circulation in such sensitizing events, to enable the administration of optimum amount of antiD immunoglobulin to prevent the mother from being sensitized, and to prevent HDFN in subsequent Rh-positive pregnancies. This low cost acid elution method for FMH testing and a modification of the Kleihauer-Betke (KB) are unavailable in most settings in sub Saharan Africa [4] despite being affordable and not requiring any sophisticated equipment like the more expensive flow cytometric method [5].

SSA is, geographically, the area of the continent of Africa that lies in south of the Sahara. Politically, it consists of all African countries that are fully or partially located in south of the Sahara. It is not known to what extent these factors affect the provision of quality immunohaematology care offered to Rh-negative pregnant population in SSA. The aim of this review is to highlight the challenges associated with the effective management of pregnancy, abortion, ruptured ectopic pregnancy and miscarriages in SSA. Evidence-based data from this review can potentially facilitate the formulation of relevant policies aimed at optimizing the management of potentially sensitizing events during pregnancy among Rhesus negative women in SSA.

\section{CHALLENGE OF LACK OF UNIVERSAL ACCESS TO PROPHYLACTIC IMMUNOGLOBULIN D IN SSA}

The Rhesus blood group system is the second most clinically significant blood group system after the ABO blood group system. The most important and clinically significant antigen of the $\mathrm{Rh}$ blood group system is the $\mathrm{RhD}$ antigen. Individuals who have the $\mathrm{RhD}$ antigen on their red cells are term RhD-positive, whereas those who do not are said to be RhD-negative. The development of $\mathrm{D}$ antibodies results from fetomaternal sensitization occurring in Rhesus D negative woman who carry a Rhesus D positive foetus. Potentially sensitizing events include; abortion, ectopic pregnancy and miscarriage. Sensitization is unlikely to affect the first pregnancy but may result in HDFN during subsequent RhD-positive pregnancy. In its mildest form the infant has sensitized RBCs, which are detectable only in laboratory tests (direct antiglobulin test), may result in jaundice, anaemia, developmental problems and intrauterine death [6]. The RhD-negative phenotype is low among Africans; $4.44 \%$ in Nigeria [7], $3.9 \%$ in Kenya [8], $4.06 \%$ in Guinea [9] and $2.4 \%$ in Cameroon [10] and significantly lower compared to prevalence of about $14 \%$ observed among Caucasians [11]. The incidence of Rhesus D haemolytic disease resulting from fetomaternal haemorrhage (FMH) occurring 
in Rhesus negative women who carry a Rhesus positive foetus continue to be high. In most countries in SSA, there are challenges associated with the management of sensitizing events (abortion, ectopic pregnancy and miscarriage) associated with $\mathrm{Rh}$ negative women [12]. A previous report indicated that despite poor access, anti-D prophylaxis is effective in the prevention of HDFN [13]. The utilization rate of anti-Rh antiserum in South African population groups for the years 1983-1985 was investigated. The crude utilization rate of anti-Rh antiserum was $41 \%$ - $44 \%$ for all population groups combined. The rate for Blacks, Whites, Indians, and Coloreds was 14\% $20 \%, 89 \%-94 \%, 59 \%-64 \%$, and $45 \%$ - 51\%, respectively [14]. The potential risk of Rhesus alloimmunization and the ensuing risk of foetal death with increasing parity were investigated in two groups Mozambican parturients (primiparous and grand multiparous). The difference did not reach statistical significance [15]. A previous report from Zimbabwe indicated that anti-D immunoglobulin remains the most important alloantibody causing HDFN, regardless of the availability of anti-D immunoglobulin for prophylaxis and suggests that all pregnant women at booking should have an antibody screen [16]. A report from Nigeria has shown that isoimmunization due to $\mathrm{Rh}$ incompatibility is poorly studied among Nigerian women and indicates the urgent need for a management protocol for anti-D immunoglobulin for prophylaxis [17]. Care management with anti-D prophylaxis in patients presenting with severe alloimmunization is difficult to access in SSA [18]. Beyond the challenge of access to anti-D prophylaxis, there is lack of alloimmunization prevention during illegal abortions and poor documentation of adequate information in patients' medical notes. Despite guidelines on Rhesus immunoprophylaxis, isoimmunisation continues to occur in most settings due to a number of reasons; lack of universal access to immunoglobulin D in Rhesus negative women who experience a potentially sensitizing event during pregnancy, unaffordability and lack of facilities for the carrying out of fetomaternal haemorrhage testing. Cost and unaffordability affect the access to prophylactic immunoglobulin D among Rhesus negative women in SSA. A previous report in Singapore indicates that although obstetricians would offer anti-D prophylaxis to Rhesusnegative women who experience a potentially sensitizing event both antenatally and postnatally as recommended by guidelines, however, not every Rh-negative woman would agree to this treatment because of cost. If guidelines are followed, a non-sensitized Rhesus negative woman should receive 3 vials of anti-D immunoglobulin in an uncomplicated pregnancy (at 28, 34 weeks gestation and postnatally after delivery of a Rhesus positive baby). This 3 vials will cost about $\$ 588.56$ in Singapore. There is need to develop guidelines for Rh immunopro- phylaxis in SSA. This is one way of optimizing the care offered to Rhesus negative women in the region. The knowledge on anti-D prophylaxis among obstetricians particularly in sub Saharan Africa needs to be improved. A previous report suggest that a continual system of education to raise awareness of evidenced-based best practices as well as clinical audit on immunoprophylaxis among obstetrician will need to be implemented to prevent $\mathrm{Rh}$ isoimmunisation among $\mathrm{Rh}$ negative women [19]. These factors are highly responsible for the difficult management of Rh-negative patients [20,21]. To prevent HDFN in most developed countries, RhD-negative women have an ABO, Rhesus blood group and alloantibody screening at booking. They are given anti-D immunoglobulin between 28 and 34 weeks of gestation. At delivery, $\mathrm{RhD}$ phenotype of the new-born is determined even if $\mathrm{RhD}$ foetal genotype is known. Maternal blood is drawn for quantification of fetomaternal transfusion within 72 hours of delivery of an Rh-positive baby and the optimum amount of anti-D immunoglobulin administered [22]. Anti-D prophylaxis has significantly reduced the incidence of erythroblastosis foetalis caused by sensitization to the D-antigen and perinatal deaths from alloimmunization have fallen 100 -fold in the developed world $[23,24]$. The anti-D immununoglobulin is prepared from the plasma of immunized human donors and therefore exists in limited supply. Monoclonal anti-D antibodies have been developed to replace polyclonal anti-D and in vivo assays for these have been predominantly based on their ability to clear erythrocytes from the maternal circulation [25]. Although the implementation of a program of routine antenatal anti-D prophylaxis (RAADP) has led to a significant decline in the residual numbers of women becoming sensitized in most developed countries, a significant number of women are not fortunate enough to have access in SSA and thus continue to be affected. This is an ethical issue of utmost public health importance.

\section{CHALLENGE OF UNSAFE ABORTION IN SSA}

Over the last decade, the World Health Organization has developed a systematic approach to estimate the regional and global incidence of unsafe abortion. Estimates indicate that 19 million unsafe abortions take place each year $[26,27]$ resulting in the deaths of about 70,000 women majority of them occurring in developing countries without skilled providers, adequate facilities and easy access. Approximately one in ten pregnancies ends in an unsafe abortion, giving a ratio of one unsafe abortion to about seven live births [28]. There is increasing incidence and trends of induced abortion, both safe and unsafe particularly in developing countries [29]. Unsafe abortion is preventable and yet remains a significant cause of ma- 
ternal morbidity and mortality in SSA. Information on incidence of induced abortion is crucial for identifying policy and programmatic needs aimed at reducing unintended pregnancy. Because unsafe abortion is a cause of maternal morbidity and mortality, measures of its incidence are also important for monitoring progress towards Millennium Development Goal 5 [30]. Medical termination and induced abortion is common and largely performed under clandestine and unsafe conditions in most settings in SSA. Complications from such procedures contribute significantly to maternal morbidity and mortality in the country [31]. There is high maternal mortality and morbidity associated with unsafe abortion in many countries in SSA and there is increasing advocacy for improvement in contraceptive use and safe abortion services [32]. The cause of death is predominantly sepsis and haemorrhage. Abortion-related mortality is a major contributor to maternal mortality in most settings with induced unsafe abortion constituting the bulk of the burden. Improved access to family planning and reproductive health services may reduce abortion-related maternal deaths [33]. Over $40 \%$ of unsafe abortions among adolescents in the developing world occur in SSA, where one in four unsafe abortions takes place during adolescence. Young women $(<25$ years $)$ in SSA, those over age 25 in Asia and women aged 20 - 35 years in Latin America and the Caribbean are in the greatest need of interventions to prevent unsafe abortion and good quality post-abortion care [34]. Unsafe abortion is an important public health problem, accounting for $13 \%$ of maternal mortality in developing countries [35]. Of an estimated annual 70,000 deaths from unsafe abortion worldwide, over $99 \%$ occur in the developing countries of sub-Saharan Africa, Central and Southeast Asia, and Latin America and the Caribbean. Factors associated with increased maternal mortality from unsafe abortion in developing countries include inadequate delivery systems for contraception needed to prevent unwanted pregnancies, restrictive abortion laws, pervading negative cultural and religious attitudes towards induced abortion, and poor health infrastructures for the management of abortion complications [35].

Abortions performed by persons lacking the requisite skills or in environments lacking minimal medical standards or both are considered unsafe and is prevalent in most countries in SSA. It is estimated that over 20 million unsafe abortions are performed annually and about 70,000 women die globally as a result, with the majority occurring in the developing world [36]. Complications from unsafe abortion are believed to account for the largest proportion of hospital admissions for gynaecological services in developing countries. The WHO estimates that one in eight pregnancy-related deaths result from unsafe abortions. The social stigma and legal re- strictions associated with abortion in many countries means that it is under reported and data on the magnitude of this problem are scarce [37]. Forty per cent of the world's women are living in countries with restrictive abortion laws, which prohibit abortion or only allow abortion to protect a woman's life or her physical or mental health. In countries where abortion is restricted, women have to resort to clandestine interventions to have an unwanted pregnancy terminated. As a consequence, high rates of unsafe abortion are seen. In SSA, unsafe abortion occurs at rates of 18 - 39 per 1000 women [38]. Integrated family health education, Planned Parenthood and contraceptive education, a mass literacy campaign and improvement of the existing national health services are recommended in order to ameliorate the problems of illegally induced abortion in SSA [39].

The prophylactic use of $\mathrm{Rh}$ immune globulin has been a medical success, protecting women who need an abortion, are Rhesus negative and could be at risk from exposure to the $\mathrm{Rh}(\mathrm{D})$ antigen of her developing foetus [40]. Evidenced-based best practice in the developed world recommend the use of prophylactic $\mathrm{Rh}$ immune globulin in all Rh-negative women in the first trimester presenting with spontaneous abortions and those undergoing medical or therapeutic termination of pregnancy to prevent maternal sensitization to the foetal $\mathrm{Rh}$ antigen and subsequent foetal morbidity and mortality [41-42]. From the 6th week of pregnancy, blood containing Rhesus antigens may be infused into the maternal circulation and cause sensitization. In case of miscarriage, abortion, ectopic pregnancy and cystic mole the chance of fetomaternal transfusion occurring, followed by sensitization of the mother is significantly increased. Therefore immunoprophylaxis with anti-D-immunoglobins should be performed in all these cases. Despite the recommendation that post-abortion $\mathrm{Rh}$ negative women receive prophylaxis with $\mathrm{Rh}$ immune globulin, an insignificant residual $\mathrm{Rh}$ immunization continue to occur in Rh-negative women particularly in SSA because of lack of universal access to prophylactic immunoglobulin D [43]. It is recommended that Rhesus negative women who have an abortion post 20 weeks as well as Rhesus negative women presenting with ruptured ectopic have fetomaternal haemorrhage testing and have adequate administration of prophylactic anti-D to prevent Rh isoimmunisation in these women [44]. This aim of this test is to determine the volume of foetal red cells that has entered maternal circulation and to enable the administration of optimum dose of prophylactic anti-D to prevent sensitization of the mum. In Canada, it is recommended that all pregnant women (D-negative or D-positive) should be typed and screened for alloantibodies with an indirect antiglobulin test at the first prenatal visit and again at 28 weeks. Anti-D Ig 300 microg IM or IV 
should be given within 72 hours of delivery to a postpartum non-sensitized Rh-negative woman delivering an Rh-positive infant. Additional anti-D Ig may be required for fetomaternal haemorrhage $(\mathrm{FMH})$ greater than $15 \mathrm{~mL}$ of foetal red blood cells (about $30 \mathrm{~mL}$ of foetal blood). After miscarriage or threatened abortion or induced abortion during the first 12 weeks of gestation, non-sensitized D-negative women should be given a minimum anti-D of 120 microg. After 12 weeks' gestation, they should be given 300 microg. At abortion, blood type and antibody screen should be done unless results of blood type and antibody screen during the pregnancy are available, in which case antibody screening need not be repeated. Anti-D should be given to non-sensitized D-negative women following ectopic pregnancy. A minimum of 120 microg should be given before 12 weeks' gestation and 300 microg after 12 weeks' gestation [45].

Vacuum curettage is a recent innovation and is demonstrably superior to other methods for first-trimester abortions. However this procedure predisposes Rhesus negative women to risk of sensitization by the Rhesus positive red cell of the foetus. Evidenced-based best practice in most developed countries makes it mandatory for all women who require an abortion to have mandatory laboratory tests particularly $\mathrm{Rh}$ blood group. All such women who are Rh-negative must receive anti-D (Rh0) immunoglobulin [46]. Countries in SSA will need to update their protocol to include this evidenced-based best practice aimed at preventing the risk of HDFN in subsequent Rh negative pregnancy involving a Rhesus positive baby. Evidenced-based guidelines in developed economies recommend that $\mathrm{Rh}$-negative women be given an injection of anti-D immunoglobulin after the termination of pregnancy procedure to prevent blood incompatibility complications in future pregnancies. This best practice is not available to a vast majority of Rhesus negative women in SSA. However, unsafe abortion, defined by the World Health Organization as a procedure for terminating an unwanted pregnancy either by persons lacking the necessary skills or in an environment lacking the minimal medical standards, or both, is prevalent and continues to put Rh-negative women who cannot afford anti$\mathrm{D}$ immunoglobulin at risk of $\mathrm{Rh}$ isoimmunisation in many settings in SSA [47]. A broad array of personnel perform unsafe termination of pregnancy in SSA. Aside from the woman herself and physicians working at clandestine sites or in hospital operating theatres after normal working hours. Others with medical experience include midwives, traditional birth attendants, pharmacists and nurses. Most worrisome are "untrained quacks" whose motives may be financial and their skills negligible. Women who are Rh-negative should be given an injection of human anti-D immunoglobulin after the termination of pregnancy procedure unless the father of the foe- tus is also Rh-negative. This prevents blood incompatibility complications in future pregnancies [48]. The costs associated with providing routine antenatal anti-D prophylaxis are predominantly the cost of the anti-D immunoglobulin IgG and the cost of treatment administration. The price of anti-D Immunoglobulin differs according to its manufacturers: Bio Products Laboratory (BPL; Elstree, UK) offers anti-D IgG at a unit price of $£ 27$ (US\$41) for $500 \mathrm{IU}$ vial [49] while Baxter Healthcare (Deerfield, IL) [50] anti-D IgG is offered at a unit price of $£ 23.90$ (US\$36) for a 1250 IU vial. Offering antenatal anti-D prophylaxis will cost an Rh-negative woman $£$ 47.80 (US\$72) to $£ 54$ (US\$82) per uncomplicated pregnancy depending on whether she is administered the BPL or Baxter product at 28 and 34 weeks. Cost-effective analysis indicates that offering routine antenatal anti-D prophylaxis to RhD-negative women is economical and results in a marked impact upon the death rate associated with HDFN [51]. Drug manufacturers need to be more humane by reducing the cost of providing anti-D prophylaxis particularly in low-income countries in SSA. Cost constraints have remained a limiting factor preventing Rhesus negative women from access to best possible treatment and care in SSA like their counterparts in most developed countries. There is the urgent need for African leaders to take up the bold challenge to provide universal access to anti-D prophylaxis for Rh-negative women. Per capita income in most settings is SSA is low and continues to affect affordability to prophylactic anti$\mathrm{D}$ treatment. In the absence of anti-D prophylaxis to prevent incidence of HDFN, options such as exchange blood transfusion and intrauterine transfusion (IUT) can significantly reduce mortality and prevent stillbirths. However, safety of blood and blood products remains a great concern. One of the biggest challenges to blood safety particularly in SSA is accessing safe and adequate quantities of blood and blood products. Societies in Africa face several enduring challenges; chronic blood shortages, high prevalence of transfusion-transmissible infection, absence of national blood transfusion service, recruitment and retention of voluntary non-remunerated donors, lack of appropriate infrastructure, trained personnel, and financial resources to support the running of a safe blood transfusion service [52]. Table 1 shows the sensitising events during $\mathrm{Rh}$ negative pregnancy for which anti-D immunoglobulin in indicated.

\section{ECTOPIC PREGNANCY IN RH NEGATIVE WOMEN}

Ectopic pregnancy is a life-threatening gynaecological emergency, and a significant cause of maternal morbidity and mortality in most settings in SSA. Ectopic pregnancy is a recognized cause of maternal morbidity and mortality and has remained a reproductive health challenge to 
Table 1. Sensitising events during Rh negative pregnancy for which anti-D immunoglobulin in indicated.

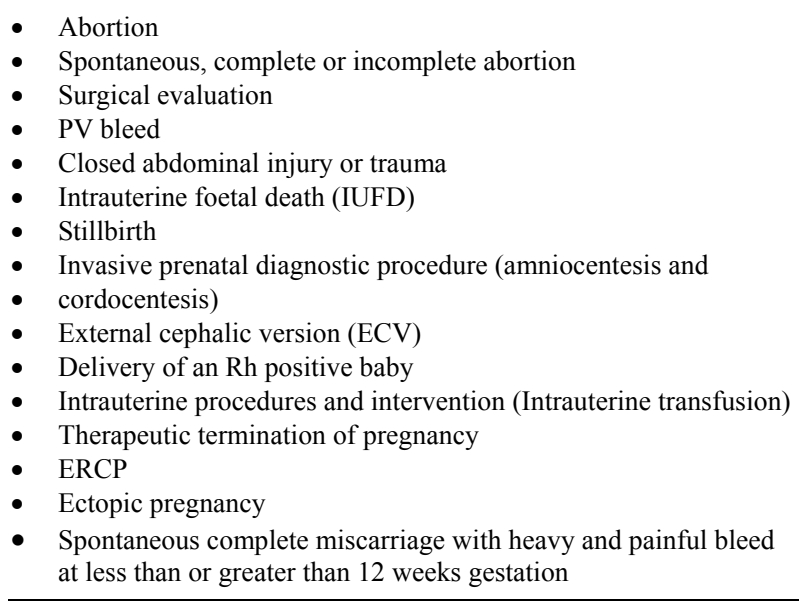

women, as well as a threat to efforts in achieving the UN's Millennium Development Goal 5 in SSA [53]. It is the leading cause of maternal mortality in the first trimester and accounts for $10 \%-15 \%$ of all maternal deaths [54]. Ectopic pregnancy is an important cause of maternal morbidity and mortality especially in developing countries, where the majority of patients present late with ruptured ectopic and haemodynamic compromise [55]. It is also a cause of foetal wastage and has been associated with recurrence and impairment of subsequent fertility [56,57]. Currently, the overall incidence is increasing worldwide [58-60]. This might be due to a combination of increasing pelvic inflammatory disease (PID), an increase in ovulation induction, assisted reproductive technology, and improved diagnostic techniques $[61,62]$. The reported incidence of this life-threatening condition varies from $0.67 \%$ in western countries to $0.9 \%-4.38 \%$ in SSA $[63,64]$.

Ectopic pregnancy in Rhesus negative women is sub optimally managed in most settings in SSA. Policies on the administration of prophylactic immunoglobin $\mathrm{D}$ to prevent the $\mathrm{Rh} \mathrm{D}$ isoimmunisation is often lacking, there is no universal access to prophylactic immunoglobulin D and affordability of prophylactic immunoglobin D is a major challenge. The Royal College of Obstetricians and Gynaecologists' (RCOG) guidelines on management of ectopic pregnancies recommends that following the incidence of ruptured ectopic pregnancy in Rhesus negative women with no anti-D alloantibodies, anti-D immunoglobulin should be administered. A retrospective case note analysis of 105 suspected cases of ectopic pregnancies reviewed using local guidelines developed from the RCOG guidance, indicated that a total of $86.7 \%$ of nonsensitized Rhesus negative women received anti-D immunoglobulin [65]. In most developed countries, it is recommended that following the incidence of ruptured ectopic pregnancy in Rhesus Negative women with no
anti-D antibodies, anti-D immunoglobulin should be administered. First trimester indications of 50 microg immunoglobulin D is recommended in cases of ectopic pregnancy. Timing for the administration of the anti-D is as soon as possible, but no later than 72 hours after the event for optimum effect [66]. It is however still reasonable to administer IgG anti-D within 13 days, and in special cases, administration is still recommended up to a maximum interval of 28 days postpartum [67]. First trimester indications (IgG anti-D sufficient dose of $50 \mu \mathrm{g}$ ) is indicated in the following conditions; termination of pregnancy, spontaneous abortion followed by instrumentation, ectopic pregnancy, chorionic villus sampling, partial molar pregnancy.

\section{CHALLENGE ASSOCIATED WITH THE POOR MANAGEMENT OF MISCARRIAGE IN RHESUS NEGATIVE WOMEN IN SSA}

Vaginal bleeding occurs in one in five of recognized pregnancies before the 20th week gestation and of these, over half end in a miscarriage [68]. Miscarriage is the spontaneous end of a pregnancy before foetal viability. Threatened miscarriage is the most common complication of early pregnancy. Approximately 1 in 9 pregnancies end in spontaneous first trimester miscarriage [69]. Most clinically apparent miscarriages (two thirds to three-quarters in various studies) occur during the first trimester. Management options can either be expectant, medical or surgical. Expectant management allows spontaneous passage of retained products of conception. Most of these cases $(65 \%-80 \%)$ will pass naturally within two to six weeks [70] and thus avoids the side effects and complications associated with medications and surgery [71] but increases the risk of mild bleeding, need for unplanned surgical treatment, and incomplete miscarriage. Medical management usually consists of using a prostaglandin (misoprostol) to encourage completion of the natural process. Surgical treatment is most commonly by vacuum curettage or dilation and curettage (D \& C) and shortens the duration and heaviness of bleeding, and avoids the physical pain associated with the miscarriage [72]. Many women who present to the accident and emergency (A \& E) department with a threatened miscarriage of less than 12 weeks gestation have heavy or recurrent bleeding or associated abdominal pain. Evidenced-based best practice recommends that all such women should have their blood group determined and anti-D should be given to those who are Rhesus negative. These patients have an increased risk of fetomaternal haemorrhage and the consequent development of HDFN. It should be mandatory for the A \& E departments to record the Rhesus status and offer anti-D immunoglobulin to all non-immune $\mathrm{Rh} \mathrm{D}$ negative women presenting 
with a threatened miscarriage less than or greater than 12 weeks' gestation [73]. It is essential that there is a policy for treating $\mathrm{Rh}$ negative women who are at risk of Rhesus immunization resulting in HDFN [73]. There is increasing advocacy that prophylactic immunoglobulin D be administered to cover all abortions irrespective of the gestational age [74]. A previous study indicated that there is need to offer anti-D immunoglobulin to all non-immune $\mathrm{Rh}$ negative women presenting with a threatened miscarriage at less than 12 weeks gestation [73]. Approximately $4 \%$ of women who have a therapeutic or complete miscarriage will have a transplacental haemorrhage of $>0.2$ millilitres of foetal red cells and of these patients, 4\% - 5\% will become sensitized [74]. It has been shown in previous report that sensitization can occur in up to $3 \%$ of Rhesus negative women exposed to a trans placental haemorrhage involving as low as $<0.1 \mathrm{ml}$ of $\mathrm{Rh}$ positive foetal red cells [75]. It is vital that adequate volume of anti-D is administered to these women to prevent them from being sensitized. A retrospective study made on the use of anti-D in an accident and emergency (A \& E) department recommend the introduction of a practical method of reminding medical staff to give anti-D to patients who are Rhesus negative and present to A \& E with miscarriage. Study indicated that 8/29 patients were put potentially at risk of $\mathrm{Rh} \mathrm{D}$ isoimmunisation. They had their blood group determined and were discharged from the department and none of the Rhesus negative patients was given anti-D [76]. Deaths from Rhesus (Rh) haemolytic disease dropped steeply particularly in the developed after anti-D immunoglobulin became available for prophylaxis [77]. Nevertheless, Rh incompatibility remains a cause of perinatal mortality and some unregistered foetal deaths before 28 weeks gestation particularly in SSA because of unaffordability $[78,79]$. Administration of anti-D immunoglobulin (Ig) is recommended after spontaneous miscarriage in an $\mathrm{Rh}-$ negative woman with no anti-D antibodies [80]. Countries in SSA need to implement these evidence-based best practices. The knowledge of medical staff in A \& E on the effective management of miscarriages in Rhesus negative women needs to be optimised. Policies on mandatory determination of blood group in all women presenting with miscarriages and administration of prophylactic immunoglobulin $\mathrm{D}$ should be implemented as a matter of urgency in SSA to reduce the risk of Rhesus (Rh) haemolytic disease. If bleeding continues intermittently after 12 weeks gestation, anti-D immunoglobulin should be given at six weekly intervals. A minimum dose of $250 \mathrm{IU}$ of anti D is required to clear $2 \mathrm{ml}$ of foetal bleed. Anti-D should preferably be administered deep into the deltoid muscle to facilitate optimum absorption as soon as possible after the sensitizing event. If anti-D is not given within the first 72 hours, a dose given within 9
- 10 day may still offer some protection. Management of Rhesus negative women in most settings in SSA is challenging. There is no policy on universal access to prophylactic immunoglobulin D. Even when prescribed, many patients cannot afford them. The net result of this failure in stewardship by health authorities is that the incidence Rhesus (D) haemolytic disease is on the increase and a cause of neonatal mortality in the region.

\section{CHALLENGES OF LACK OF FACILITIES TO CARRY OUT FETOMATERNAL HAEMORRHAGE TESTING (FMH)}

Kleihauer Betke test is a test that detects foetal cells in the maternal blood and help prevent the development of $\mathrm{RhD}$ alloimmunisation in subsequent pregnancy. The KB test is a blood test used to measure the amount of foetal red cells transferred from a foetus to a mother's bloodstream [81]. It is usually performed on Rh-negative mothers to identify women with a large fetomaternal haemorrhage ( $>4 \mathrm{~mL}$ of packed foetal RBCs) who may need additional anti-D immunoglobulin to ensure complete clearance of all foetal RBCs from maternal circulation and thus prevent them from being sensitized to produce immune antibodies against D-antigen on the surface of the foetal RBCs. A standard dose of $125 \mathrm{IU}$ is the required dose of Anti-D immunoglobulin required to inhibit $1 \mathrm{~mL}$ bleed of foetal RBCs and thus prevent the formation of Rh-antibodies in the mother and prevent $\mathrm{Rh}$-disease in future Rh-positive children. The KB test is the standard method of detecting FMH. It takes advantage of the differential resistance of foetal haemoglobin to acid elution. A standard blood smear is prepared from the mother's blood, and exposed to an acid bath. This removes adult haemoglobin, but not foetal haemoglobin, from the RBCs. Subsequent staining with eosin makes foetal cells (containing foetal haemoglobin) appear rosepink in colour, while adult RBCs are only seen as "ghosts". A large number of cells $(>5000)$ are counted under the microscope and a ratio of foetal to maternal cells generated. In those with positive tests, follow-up testing as a postpartum check should be done to rule out the possibility of a false positive. This could be caused by a process in the mother which causes persistent elevation of foetal haemoglobin; sickle cell trait and hereditary persistence of foetal haemoglobin (HPFH). Comparison with other more expensive or technologically advanced methods such as flow cytometry has shown that the KB test, like the more advanced methods, is sensitive for the detection of FMH [82]. Performance indicators for the $\mathrm{KB}$ test during antepartum period in most developed countries include: unexpected/unexplained still birth, significant maternal abdominal trauma, post 20 weeks gestation vaginal bleed, post 20 weeks therapeutic 
termination of pregnancy, miscarriage, in utero therapeutic interventions, external cephalic version, and antepartum haemorrhage [83]. Testing at the time of birth and postpartum is indicated if baby is Rh-positive. A cord sample is collected from all babies born of Rh-negative mothers. If the cord sample is Rh (D)-positive, a KB or flow cytometric determination of FMH is carried out and anti-D immunoglobulin optimal to clear the volume of FMH is administered preferably within 72 hours of delivery [84]. If recurrent uterine bleeding occurs in a Dnegative woman after 20 weeks gestation, anti-D immunoglobulin will be required at a minimum of 6-weekly intervals. An FMH test should be performed every 2 weeks and if FMH is detected, additional anti-D will be required [85]. Since foetal and maternal blood cells have the same life expectancy in the maternal bloodstream, it is possible to obtain informative results from a $\mathrm{KB}$ stain for a fair period of time after a stillbirth. However, if the mother and foetus are ABO incompatible, it is more crucial to quickly perform the KB stain following a stillbirth, as the foetal RBCs will be eliminated from the maternal bloodstream very quickly, causing the $\mathrm{KB}$ stain to underestimate the degree of $\mathrm{FMH}$, if any. The KB technique, based on acid elution of maternal RBCs, is the most widely used technique in the developed world for estimating the volume of FMH and for determining the need for additional doses of anti-D immunoglobulin to prevent maternal alloimmunization [86]. Finally, anything that causes persistence of foetal haemoglobin in maternal blood cells will make interpretation much trickier. Certain haemoglobinopathies, the most common of which is sickle cell trait, and HPFH do this. The KB test has been used worldwide since the 1950s to quantify the FMH and to ensure that an appropriate dose of anti-D immunoglobulin is administered both antenatally and postnatally to RhD-negative women to prevent Rh alloimmunization. Despite being a simple test to perform, cheap, require essentially a light microscope, glass slide and stains compared to the more expensive and more sophisticated-equipment requiring flow cytometric method, it is unavailable in most settings in SSA. The comparability of results of 957 samples was assessed using a standardized KB technique and flow cytometry. Results suggest that if careful attention is paid to performing a standardized $\mathrm{KB}$ test, then it is of value in estimating the size of FMH, and that flow cytometry may be of additional value for cases in which the Kleihauer result is equivocal or indicates that a large FMH has occurred which requires the administration of additional anti-D immunoglobulin [87]. Similarly Johnson and colleagues [88] evaluated an indirect immunofluorescence flow cytometry technique in a series of patients with large FMH. Patient samples identified by KB testing as having FMH $>4 \mathrm{~mL}$ were sent for flow cytometric analysis. The re- port indicated that flow cytometry is helpful for the accurate quantification and management of patients with large FMH, in cases of HPFH and can potentially produce a worthwhile reduction in the use of anti-D immunoglobulin [89]. Simultaneous assessment of the volume of fetomaternal haemorrhage (FMH) to specify the dose is suitable. The FMH volume assessment determine the volume of foetal erythrocytes (red blood cells, RBCs) which has entered maternal circulation and enables the intramuscular administration of optimum quantity of anti-D (Figure 1).

\section{CONCLUSION}

Despite the fact that the prevalence of $\mathrm{Rh}$-negative phenotype is significantly lower among Africans compared to Caucasians, the prevalence of Rhesus D HDFN is on the rise in some settings in SSA and $\mathrm{Rh}$ alloimmunization remains a major factor responsible for perinatal morbidity. This may result in the compromise of the women's obstetric care due to the unaffordability of prophylactic anti-D immunoglobulin. There is a need for the implementation of universal access to anti-D immunoglobulin for the Rh-negative pregnant population in SSA. Anti-D immunoglobulin should be available in cases of potentially sensitizing events antenatally and postnatally. There should be provision of facilities for FMH measurements following potentially sensitizing events post 20 weeks gestation in Rhesus negative women in the region. The low-cost acid elution method, and a modification of the Kleihauer-Betke (KB) test, should become readily available, affordable, and minimum alternatives to flow cytometric measurement of FMH. Knowledge of anti-D prophylaxis among obstetricians, biomedical scientist, midwives, traditional birth attendants, pharmacists, and nurses in SSA needs to be optimized. This will facilitate

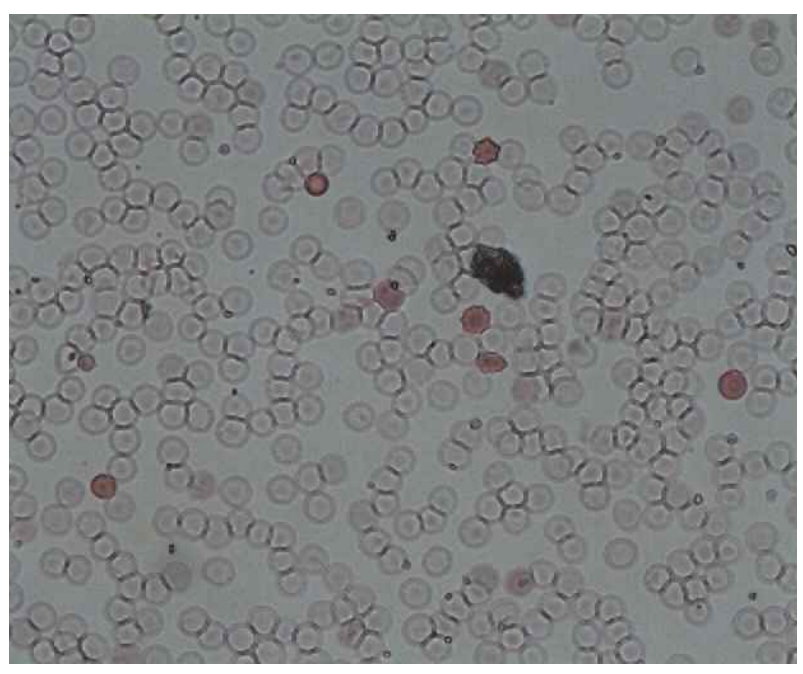

Figure 1. Slide showing a positive Kleihauer result with pink stained foetal cells. 
quality antenatal and postnatal care offered to Rh-negative pregnant population and improve perinatal outcomes.

\section{REFERENCES}

[1] Daniels, G., Finning, K., Martin, P. and Summers, J. (2006) Foetal blood group genotyping: Present and future. Annals of the New York Academy of Sciences, 1075, 8895. http://dx.doi.org/10.1196/annals.1368.011

[2] (2002) Pregnancy and routine anti-D prophylaxis for D-negative women. Nice, May.

[3] Harkness, M., Freer, Y., Prescott, R.J. and Warner, P. (2008) Implementation of NICE recommendation for a policy of routine antenatal anti-D prophylaxis: A survey of UK maternity units. Transfusion Medicine, 18, 292295. http://dx.doi.org/10.1111/j.1365-3148.2008.00882.x

[4] Katiyar, R., Kriplani, A., Agarwal, N., Bhatla, N. and Kabra, M. (2007) Detection of fetomaternal haemorrhage following chorionic villus sampling by Kleihauer Betke test and rise in maternal serum alpha feto protein. Prenatal Diagnosis, 27, 139-142. http://dx.doi.org/10.1002/pd.1632

[5] Johnson, P.R., Tait, R.C., Austin, E.B., Shwe, K.H. and Lee, D. (1995) Flow cytometry in diagnosis and management of large fetomaternal haemorrhage. Journal of Clinical Pathology, 48, 1005-1008.

http://dx.doi.org/10.1136/jcp.48.11.1005

[6] Knowles, S. and Poole, G. (2002) Human blood group systems. In: Murphy, M.F. and Pamphilon, D.H., Eds., Practical Transfusion Medicine, Blackwell Science, London, 24-31.

[7] Jeremiah, Z.A. (2005) An assessment of the clinical utility of routine antenatal screening of pregnant women at first clinic attendance for haemoglobin genotypes, haematocrit, ABO and Rh blood groups in Port Harcourt, Nigeria. African Journal of Reproductive Health, 9, 112-117. http://dx.doi.org/10.2307/3583417

[8] Mwangi, J. (1999) Blood groups distribution in an urban population of patient targeted blood donors. East African Medical Journal, 76, 615-618.

[9] Loua, A., Lamah, M.R., Haba, N.Y. and Camara, M. (2007) Frequency of blood groups ABO and Rhesus D in the Guinean population. Transfusion Clinique et Biologique, 14, 435-439.

http://dx.doi.org/10.1016/j.tracli.2007.12.008

[10] Tagny, C.T., Fongué, V.F. and Mbanya, D. (2009) The erythrocyte phenotype in $\mathrm{ABO}$ and $\mathrm{Rh}$ blood groups in blood donors and blood recipients in a hospital setting of Cameroon: Adapting supply to demand. Revue Médicale de Bruxelles, 30, 159-162.

[11] Bergstrom, S., Pereira, C., Hagstrom, U. and Safwenberg, J. (1994) Obstetric implications of rhesus antigen distribution in Mozambican and Swedish women. Gynecologic and Obstetric Investigation, 38, 82-86. http://dx.doi.org/10.1159/000292454

[12] Correa, P., Linhard, J., Diebolt, G. and Diadhiou, F. (1969) Study of bilirubin in amniotic fluid associated with fetomaternal isoimmunization at Dakar. Bulletin de la Société Médicale d'Afrique Noire de Langue Française, 14, 262-266.

[13] Verkuyl, D.A. (1987) Economics of anti-rhesus prophylaxis in an African population. Central African Journal of Medicine, 33, 32-37.

[14] Hitzeroth, H.W. and Op't Hof, J. (1988) On the prevention of rhesus immunisation in the RSA. South African Medical Journal, 19, 502-506.

[15] Pereira, C., Axemo, P., Bergström, S. and Säfwenberg, J. (1992) Parity-related prevalence of Rhesus antigens among Mozambican parturients. Gynecologic and $\mathrm{Ob}$ stetric Investigation, 34, 129-132. http://dx.doi.org/10.1159/000292744

[16] Cakana, A.Z. and Ngwenya, L. (2001) Is antenatal antibody screen worthwhile in the Zimbabwean Population? Central African Journal of Medicine, 47, 26-28.

[17] Kotila, T.R., Odukogbe, A.A., Okunlola, M.A., Olayemi, O. and Obisesan, K.A. (2005) The pregnant Rhesus negative Nigerian woman. Nigerian Postgraduate Medical Journal, 12, 305-307.

[18] Toure, E.A., Horo, F.M., Sein, K., Konan, B.R. and Kone, M. (2006) Management of rhesus alloimmunisation by spectrophometry: About one case at the Yopougon Teaching Hospital, Côte-d'Ivoire. Bulletin de la Société de Pathologie Exotique, 99, 245-249.

[19] Wee, W.W. and Kanagalingam, D. (2009) The use of anti-D immunoglobulins for Rhesus prophylaxis: Audit on knowledge and practices among obstetricians. Singapore Medical Journal, 50, 1054-1057.

[20] Darmstadt, G.L., Lee, A.C., Cousens, S., et al. (2009) 60 million non-facility births: Who can deliver in community settings to reduce intrapartum-related deaths? International Journal of Gynecology \& Obstetrics, 107, S89S112. http://dx.doi.org/10.1016/j.ijgo.2009.07.010

[21] Belinga, S., Ngo, S.F., Bilong, C., Manga, J., Mengue, M.A. and Tchendjou, P. (2009) High prevalence of anti$\mathrm{D}$ antibodies among women of childbearing age at Centre Pasteur of Cameroon. African Journal of Reproductive Health, 13, 47-52.

[22] Cortey, A. and Brossard, Y. (2006) Prevention of fetomaternal rhesus-D allo-immunization. Practical aspects. Journal de Gynécologie, Obstétrique et Biologie de la Reproduction (Paris), 35, S123-S130. http://dx.doi.org/10.1016/S0368-2315(06)76509-7

[23] Urbaniak, S. (1998) The scientific basis of antenatal prophylaxis. BJOG: An International Journal of Obstetrics \& Gynaecology, 105, 11-18. http://dx.doi.org/10.1111/j.1471-0528.1998.tb10286.x

[24] Fung, K.F.K., Eason, E., Crane, J., et al. (2003) MaternalFetal Medicine Committee, Genetics Committee. Prevention of Rh alloimmunization. Journal of Obstetrics \& Gynaecology, 25, 765-773.

[25] Beliard, R. (2006) Monoclonal anti-D antibodies to prevent alloimmunization: Lessons from clinical trials. Transfusion Clinique et Biologique, 13, 58-64. http://dx.doi.org/10.1016/j.tracli.2006.03.013

[26] Grimes, D.A. (2003) Unsafe abortion: The silent scourge. 
British Medical Bulletin, 67, 99-113. http://dx.doi.org/10.1093/bmb/ldg002

[27] Dixon-Mueller, R. (1990) Abortion policy and women's health in developing countries. International Journal of Health Services, 20, 297-314. http://dx.doi.org/10.2190/V08N-UE7N-TNBH-RA4P

[28] Shah, I. and Ahman, E. (2009) Unsafe abortion: Global and regional incidence, trends, consequences, and challenges. Journal of Obstetrics and Gynaecology (Canada), 31, 1149-1158.

[29] Ahman, E. and Shah, I. (2002) Unsafe abortion: Worldwide estimates for 2000. Reproductive Health Matters, 10, 13-17. http://dx.doi.org/10.1016/S0968-8080(02)00012-5

[30] Sedgh, G., Henshaw, S., Singh, S., Ahman, E. and Shah, I.H. (2007) Induced abortion: Estimated rates and trends worldwide. Lancet, 370, 1338-1345. http://dx.doi.org/10.1016/S0140-6736(07)61575-X

[31] Abiodun, O.M., Balogun, O.R., Adeleke, N.A. and Farinloye, E.O. (2013) Complications of unsafe abortion in South West Nigeria: A review of 96 cases. African Journal of Medicine \& Medical Sciences, 42, 111-115.

[32] Shah, N., Hossain, N., Noonari, M. and Khan, N.H. (2011) Maternal mortality and morbidity of unsafe abortion in a university teaching hospital of Karachi, Pakistan. Journal of Pakistan Medical Association, 61, 582-586.

[33] Nwogu-Ikojo, E.E. and Ezegwui, H.U. (2007) Abortionrelated mortality in a tertiary medical centre in Enugu, Nigeria. Journal of Obstetrics \& Gynaecology, 27, 835837. http://dx.doi.org/10.1080/01443610701718883

[34] Shah, I. and Ahman, E. (2004) Age patterns of unsafe abortion in developing country regions. Reproductive Health Matters, 12, 9-17. http://dx.doi.org/10.1016/S0968-8080(04)24002-2

[35] Okonofua, F. (2006) Abortion and maternal mortality in the developing world. Journal of Obstetrics and Gynaecology (Canada), 28, 974-979.

[36] Ibrahim, I. A. and Onwudiegwu, U. (2012) Socio-demographic determinants of complicated unsafe abortions in a semi-urban Nigerian town: A four-year review. West Indian Medical Journal, 61, 163-167.

[37] Singh, S. (2006) Hospital admissions resulting from unsafe abortion: Estimates from 13 developing countries. The Lancet, 368, 1887-1892. http://dx.doi.org/10.1016/S0140-6736(06)69778-X

[38] Rasch, V. (2011) Unsafe abortion and post abortion care-An overview. Acta Obstetricia et Gynecologica Scandinavica, 90, 692-700. http://dx.doi.org/10.1111/j.1600-0412.2011.01165.x

[39] Ikechebelu, J.I. and Okoli, C.C. (2003) Morbidity and mortality following induced abortion in Nnewi, Nigeria. Tropical Doctor, 33, 170-172.

[40] Jabara, S. and Barnhart, K.T. (2003) Is Rh immune globulin needed in early first-trimester abortion? A review. American Journal of Obstetrics Gynecology, 188, 623627. http://dx.doi.org/10.1067/mob.2003.208

[41] Hannafin, B., Lovecchio, F. and Blackburn, P. (2006) Do Rh-negative women with first trimester spontaneous abortions need Rh immune globulin? American Journal of
Emergency Medicine, 24, 487-489.

http://dx.doi.org/10.1016/j.ajem.2006.01.020

[42] Dayton, V.D., Anderson, D.S., Crosson, J.T. and Cruikshank, S.H. (1990) A case of Rh isoimmunization: Should threatened first-trimester abortion be an indication for $\mathrm{Rh}$ immune globulin prophylaxis? American Journal of $\mathrm{Ob}$ stetrics \& Gynecology, 163, 63-64. http://dx.doi.org/10.1016/S0002-9378(11)90668-1

[43] Maas, D.H. (1979) Anti-D prophylaxis after abortions and interruptions. Fortschritte der Medizin, 97, 148-152.

[44] Krause, H.G. and Goh, J.T. (1996) Positive Kleihauer result following an ectopic pregnancy. Australian and New Zealand Journal of Obstetrics and Gynaecology, 36, 324-325. http://dx.doi.org/10.1111/j.1479-828X.1996.tb02721.x

[45] Fung, K.F.K., Eason, E., Crane, J., Armson, A., De La Ronde, S., Farine, D., Keenan-Lindsay, L., Leduc, L., Reid, G.J., Aerde, J.V., Wilson, R.D., Davies, G., Désilets, V.A., Summers, A., Wyatt, P. and Young, D.C. (2003) Prevention of $\mathrm{Rh}$ alloimmunization. MaternalFoetal Medicine Committee, Genetics Committee. Journal of Obstetrics Gynaecology Canada, 25, 765-773.

[46] Stubblefield, P.G. (1986) Surgical techniques of uterine evacuation in first- and second-trimester abortion. Clinics in Obstetrics and Gynaecology, 13, 53-70.

[47] Ahman, E. and Shah, I. (2002) Unsafe abortion: Worldwide estimates for 2000. Reproductive Health Matters, 10, 13-17. http://dx.doi.org/10.1016/S0968-8080(02)00012-5

[48] Rogo, K.O. (1993) Induced abortion in sub-Saharan Africa. East African Medical Journal, 70, 386-395.

[49] Bio Products Laboratory (2001) The clinical and cost effectiveness of routine antenatal prophylaxis for rhesus negative women in pregnancy. A submission to the National Institute for Clinical Excellence.

[50] Baxter Healthcare (2001) The clinical and cost effectiveness of anti-D prophylaxis for Rhesus negative women in pregnancy. Submission to the National Institute for Clinical Excellence.

[51] Chilcott, J., Tappenden, P.L., Lloyd J.M., Wight, J., Forman, K., Wray, J. and Beverley, C. (2004) The economics of routine antenatal anti-D prophylaxis for pregnant women who are rhesus negative. An International Journal of Obstetrics \& Gynaecology, 111, 903-907. http://dx.doi.org/10.1111/j.1471-0528.2004.00226.x

[52] Tagny, C.T., Mbanya, D., Tapko, J.B. and Lefrère, J.J. (2008) Blood safety in Sub-Saharan Africa: A multi-factorial problem. Transfusion, 48, 1256-1261. http://dx.doi.org/10.1111/j.1537-2995.2008.01697.x

[53] Lawani, O.L., Anozie, O.B. and Ezeonu, P.O. (2013) Ectopic pregnancy: A life-threatening gynecological emergency. International Journal of Women's Health, 5, 515521. http://dx.doi.org/10.2147/IJWH.S49672

[54] Gharoro, E.P. and Igbafe, A.A. (2002) Ectopic pregnancy revisited in Benin City, Nigeria: Analysis of 152 cases. Acta Obstetricia et Gynecologica Scandinavica, 81, 11391143. http://dx.doi.org/10.1034/j.1600-0412.2002.811207.x

[55] Panti, A., Ikechukwu, N.E., Lukman, O.O., Yakubu, A., 
Egondu, S.C. and Tanko, B.A. (2012) Ectopic pregnancy at Usmanu Danfodiyo University Teaching Hospital Sokoto: A ten year review. Annals of Nigerian Medicine, 6, 87-91. http://dx.doi.org/10.4103/0331-3131.108128

[56] Anorlu, R.I., Oluwole, A., Abudu, O.O. and Adebanjo, S. (2005) Risk factors for ectopic pregnancy in Lagos, Nigeria. Acta Obstetricia et Gynecologica Scandinavica, 84, 184-188.

[57] Igberase, G.O., Ebeigbe, P.N., Igbeboji, O.F. and Ajupo, B.I. (2005) Ectopic pregnancy: An 11-year review in a tertiary center in the Niger Delta. Tropical Doctor, 35, 175-177. http://dx.doi.org/10.1258/0049475054620888

[58] Monga, A. (2006) Ectopic pregnancy. In: Monga, A. and Baker, P., Eds., Gynaecology by Ten Teachers, 18th Edition, Hodder Education, London, 97-99.

[59] Baffoe, S. and Nkyekyer, K. (1999) Ectopic pregnancy in Korle Bu Teaching Hospital, Ghana: A three-year review. Tropical Doctor, 29, 18-22.

[60] Sivalingam, V.N., Duncan, W.C., Kirk, E., Shephard, L. A. and Horne, A.W. (2011) Diagnosis and management of ectopic pregnancy. Journal of Family Planning \& Reproductive Health Care, 37, 231-240. http://dx.doi.org/10.1136/jfprhc-2011-0073

[61] Sara, H.G. and Uzelac, P.S. (2007) Early pregnancy risks. In: DeCherney, A.H., Nathan, L., Goodwin, M.T. and Laufer, N., Eds., Current Diagnosis and Treatment: Obstetrics and Gynecology, 10th Edition, McGraw-Hill, Columbus, 259-272.

[62] Drife, J.S. (1990) Tubal pregnancy: Rising incidence, earlier diagnosis, more conservative management. BMJ, 301, 1057-1058. http://dx.doi.org/10.1136/bmj.301.6760.1057

[63] Abdul, F.I. (2000) Ectopic pregnancy in Ilorin: A review of 278 cases. Niger Journal of Medicine, 9, 92-96.

[64] Igwegbe, A., Eleje, G. and Okpala, B. (2013) An appraisal of the management of ectopic pregnancy in a Nigerian tertiary hospital. Annals of Medical and Health Sciences Research, 3, 166-170.

[65] Laiyemo, R. and Etokowo, G. (2008) Management of suspected ectopic pregnancy: An audit from East Kent NHS Hospital Trust. Journal of Obstetrics \& Gynaecology, 28, 209-212.

http://dx.doi.org/10.1080/01443610801912485

[66] Lubuský, M., Procházka, M., Simetka, O. and Holusková, I. (2010) Guideline for prevention of $\mathrm{RhD}$ alloimmunization in RhD negative women. Ceska Gynekologie, 75, 323-324.

[67] Lubušký, M., Procházka, M., Simetka, O. and Holusková, I. (2013) Guideline for prevention of RhD alloimmunizationin RhD negative women. Ceska Gynekologie, 78, 132-133.

[68] Everett, C. (1997) Incidence and outcome of bleeding before the 20th week of pregnancy: Prospective study of general practice. British Medical Journal, 315, 32-34. http://dx.doi.org/10.1136/bmj.315.7099.32

[69] Jurkovic, D. (1998) Modern management of miscarriage: Is there a place for non-surgical treatment? Ultrasound in Obstetrics \& Gynecology, 11, 161-163. http://dx.doi.org/10.1046/j.1469-0705.1998.11030161.x

[70] Kripke, C. (2006) Expectant management versus surgical treatment for miscarriage. American Family Physician, 74, 1125-1126.

[71] Tang, O.S. and Ho, P.C. (2006) The use of misoprostol for early pregnancy failure. Current Opinion in Obstetrics and Gynecology, 18, 581-586. http://dx.doi.org/10.1097/GCO.0b013e32800feedb

[72] Trinder, J., Brocklehurst, P., Porter, R., Read, M., Vyas, S. and Smith, L. (2006) Management of miscarriage: Expectant, medical, or surgical? Results of randomized controlled trial (miscarriage treatment (MIST) trial). British Medical Journal, 332, 1235. http://dx.doi.org/10.1136/bmj.38828.593125.55

[73] Weinberg, L. (2001) Use of anti-D immunoglobulin in the treatment of threatened miscarriage in the accident and emergency department. Emergency Medicine Journal, 18, 444-447. http://dx.doi.org/10.1136/emj.18.6.444

[74] Joint Working Group of the British Blood Transfusion Society and the Royal College of Obstetricians and Gynaecologist (1999) Recommendations for the use of anti$\mathrm{D}$ immunoglobulin for Rh prophylaxis. Transfusion $\mathrm{Me}$ dicine, 9, 93-97.

http://dx.doi.org/10.1046/j.1365-3148.1999.009001093.x

[75] Bowman, J.M. (1988) The prevention of Rh immunization. Transfusion Medicine Reviews, 2, 129-150. http://dx.doi.org/10.1016/S0887-7963(88)70039-5

[76] Zipurski, A. and Israels, L.G. (1967) The pathogenesis and prevention of $\mathrm{Rh}$ immunization. Canadian Medical Association Journal, 97, 1245-1257.

[77] Huggon, A.M. and Watson, D.P. (1993) Use of anti-D in an accident and emergency department. Archives of Emergency Medicine, 10, 306-309.

[78] Roberts, H. and Mitchell, R. (1991) The use of anti-D prophylaxis in the management of miscarriage in general practice. Health Bulletin, 9, 245-249.

[79] Erhabor, O. and Adias, T.C. (2010) Rhesus isoimmunisation in sub Saharan Africa indicates the need for universal access to anti Rh D immunoglobulin and effective management of D negative pregnancies. International Journal of Women's Health, 2, 429-437.

[80] Karanth, L., Jaafar, S.H., Kanagasabai, S., Nair, N.S. and Barua, A. (2013) Anti-D administration after spontaneous miscarriage for preventing Rhesus alloimmunisation. The Cochrane Database Systematic Reviews, 3, CD009617.

[81] Katiyar, R., Kriplani, A., Agarwal, N., Bhatla, N. and Kabra, M. (2007) Detection of fetomaternal haemorrhage following chorionic villus sampling by Kleihauer Betke test and rise in maternal serum alpha feto protein. Prenatal Diagnosis, 27, 139-142. http://dx.doi.org/10.1002/pd.1632

[82] NHS Evidence (2009) Guidelines for the estimation of fetomaternal haemorrhage. Working Party of the British Committee for Standards in Haematology. Transfusion Taskforce.

[83] Robson, S.C., Lee, D. and Urbaniak, S (1998) Anti-D immunoglobulin in $\mathrm{RhD}$ prophylaxis. An International Journal of Obstetrics \& Gynaecology, 105, 129-134. 
http://dx.doi.org/10.1111/j.1471-0528.1998.tb10039.x

[84] British Committee for Standards in Haematology (2006) Guidelines for the use of prophylactic anti-D immunoglobulin. BCSH.

[85] Howarth, D.J., Robinson, F.M., Williams, M. and Norfolk, D.R. (2002) A modified Kleihauer technique for the quantification of fetomaternal haemorrhage. Transfusion Medicine, 12, 373-378.

http://dx.doi.org/10.1046/j.1365-3148.2002.00406.x

[86] Duguid, J.K.M., Bromilow, I.M., Eggington, J., Martlew, V.J., McFadyen, I.R. and Clarke, C.A. (1996) Kleihauer Testing and flow cytometry. A comparative study for assessment of feto-maternal haemorrhage. Haematology, 1, 79-83.

[87] Davies, B.H., Olsen, S., Bigelow, N.C. and Chen, J.C.
(1998) Detection of foetal red cells in fetomaternal haemorrhage using a foetal haemoglobin antibody by flow cytometry. Transfusion, 38, 749-756.

http://dx.doi.org/10.1046/j.1537-2995.1998.38898375514 .X

[88] Johnson, P.R., Tait, R.C., Austin, E.B., Shwe, K.H. and Lee, D. (1995) Flow cytometry in diagnosis and management of large fetomaternal haemorrhage. Journal of Clinical Pathology, 48, 1005-1008.

http://dx.doi.org/10.1136/jep.48.11.1005

[89] Radel, D.J., Penz, C.S., Dietz, A.B. and Gastineau, D.A. (2008) A combined flow cytometry-based method for fetomaternal haemorrhage and maternal D. Transfusion, $\mathbf{4 8}$, 1886-1891.

http://dx.doi.org/10.1111/j.1537-2995.2008.01780.x 